\title{
ENTER THE FOX_LUMPING AND SPLITTING IN THE STUDY OF TRANSNATIONAL NETWORKS: A RESPONSE TO STAVROS GADINIS
}

\author{
Robert B. Abdieb*
}

Over the last two decades, the scholarly study of transnational networks has —with select exceptions—been characterized by two features.

The first is an approach to transnational networks as a relatively singular phenomenon. Networks have largely been studied as a broadly encompassing choice of institutional design-with emphasis on the common characteristics that distinguish them from other design choices, rather than those that distinguish them from one another.

In many ways, scholars' agglomeration of network institutions for analytic purposes-as opposed to their sorting into distinct categories - makes a great deal of sense. Transnational networks, to begin, remain a relatively new phenomenon in international relations, whether by comparison with more formal institutions, various and sundry political associations and military alliances, economic and free trade groupings, or other structured linkages across national boundaries. An approach to them as a particular "thing" may thus have been the most that could be done. Equally important in understanding our traditional emphasis on networks' commonalities might be their still uncertain place in the international legal regime — and a resulting instinct to focus attention on their status and position, as opposed to variations among them.

Beyond its approach to transnational networks as a singular phenomenon, the network literature has also been characterized by a strongly normative orientation. This might be seen even in the early work of Bob Keohane and Joseph Nye on the topic, and became yet more apparent in the classic writing of Anne-Marie Slaughter. ${ }^{1}$ Those who succeeded Slaughter likewise often wrote as advocates for the role of networks in transnational governance. ${ }^{2}$ This normative focus only grew as push-back against the role of networks began to emerge-including in important work by Ken Anderson, Pierre Verdier, and others. ${ }^{3}$

Stavros Gadinis' Three Pathways to Global Standards: Private, Regulator, and Ministry Networks represents an important antidote to each of these tendencies. ${ }^{4}$ Most important is Gadinis' attempt to sort the universe of transnational networks into distinct categories of institutions.

*Vice Dean \& K.H. Gyr Professor of Private International Law, Director, Center on Federalism \& Intersystemic Governance, Emory Law School. Originally published online 05 August 2015.

1 See Robert O. Keohane \& Joseph S. Nye, Transgovernmental Relations and International Organizations, 27 WorLD POL. 39 (1974); AnneMarie Slaughter, Court to Court, 92 AJIL 708 (1998).

2 See, e.g., Kal Raustiala, The Architecture of International Cooperation: Transgovernmental Networks and the Future of International Law, 43 VA. J. INT'L L. 1 (2002); David Zaring, International Law By Other Means: The Twilight Existence of International Financial Regulatory Organizations, 33 TEX. INT'L L.J. 281 (1998).

3 See, e.g., Kenneth Anderson, Squaring the Circle? Reconciling Sovereignty and Global Governance Through Global Government Networks, 118 Harv. L. Rev. 1255 (2005); Pierre-Hugues Verdier, Transnational Regulatory Networks and Their Limits, 34 YALE J. INT’L L. 113 (2009).

${ }^{4}$ Stavros Gadinis, Three Patbways to Global Standards: Private, Regulator, and Ministry Networks, 109 AJIL 1 (2015). 


\section{From Lumping to Splitting in the Study of Transnational Networks}

In his famous essay, The Hedgehog and the Fox, Isaiah Berlin offered the following insight into the history of ideas:

There is a line among the fragments of the Greek poet Archilochus which says: "The fox knows many things, but the hedgehog knows one big thing." .. . [T] aken figuratively, the words can be made to yield a sense in which they mark one of the deepest differences which divide writers and thinkers, and, it may be, human beings in general. For there exists a great chasm between those, on one side, who relate everything to a single central vision, one system less or more coherent or articulate, in terms of which they understand, think and feel-a single, universal, organizing principle in terms of which alone all that they are and say has significance-and, on the other side, those who pursue many ends, often unrelated and even contradictory, connected, if at all, only in some de facto way, for some psychological or physiological cause, related by no moral or aesthetic principle. . . . The first kind of intellectual and artistic personality belongs to the hedgehogs, the second to the foxes. ${ }^{5}$

For the network literature, Gadinis' article might be cast as fox, to the hedgehogs that came before it. Borrowing from another famous author, while the traditional approach to the study of transnational networks has been that of the "lumper," Gadinis is instead a "splitter."6 Rather than evaluate networks as a single institutional type, he seeks to dissect them into multiple types.

Gadinis is not, of course, the first to identify distinct categories of networks. Across her work, for example, Slaughter has variously focused on networks that exclude private/industry participation, and placed special emphasis on networks of judges—among other dissections of the generalized universe of networks. ${ }^{7}$ David Zaring has analogously distinguished the G-20 from traditional regulatory networks, ${ }^{8}$ while Chris Brummer casts Multilateral Memorandum of Understanding (MMOU) of the International Organization of Securities Commissions (IOSCO) as a kind of "governmental club," rather than network.

In his systematic approach to what he categorizes as private, regulator, and ministry networks; his analysis of the distinct characteristics of each category of network, and his quantitative analysis of their expansion, however, Gadinis positions himself as distinctly oriented to the project of disaggregation and categorization in the study of transnational networks. His work can thus be expected to impact the network literature in a number of ways.

At the most obvious level, Gadinis' tripartite construct of private, regulator, and ministry networks constitutes a focal point for future analysis. As I will suggest below, there are good reasons to question his categories. Gadinis points his successors in the right direction, however, and offers them a point of reference to embrace, modify, or reject.

At a deeper level, Gadinis' exercise in splitting helps to orient our attention to the distinct motivations driving distinct networks. Whatever their shared features, it would seem self-evident that networks of judges, of accountants in private practice, of national regulatory agencies, and of finance ministers must be differently motivated, in terms of their goals and priorities.

5 Isaiah Berlin, The Hedgehog and the Fox 1 (Henry Hardy ed., Princeton University Press 2013) (1953).

${ }^{6}$ See Jim Endersby, Lumpers and Splitters: Darwin, Hooker, and the Search for Order, SCIENCE, Dec. 11, 2009, at 1496 (citing Charles Darwin's letter to Joseph Dalton Hooker, distinguishing lumpers from splitters).

7 See, e.g., ANNE-Marie Slaughter, A NeW WORLd ORder (2004); Slaughter, supra note 1.

8 See David Zaring, International Institutional Performance in Crisis, 10 CHI. J. INT'L L. 475 (2010).

9 See Chris Brummer, Post-American Securities Regulation, 98 CAL. L. Rev. 327 (2010). 
In sorting the generalized universe of transnational networks into categories, Gadinis reveals the need to explore their distinct motivations. He does so in a somewhat preliminary fashion, to be sure, but it is sometimes the case that the first step really is the hardest.

Beyond motives, Gadinis' splitting also generates enhanced insight into the internal processes and other design features of transnational networks. In place of the abstraction of member consensus, we can tease out precisely when power dynamics play more or less of a role in networks. Likewise, when training and education are essential network functions. Or when autonomy from national authorities is likely to be essential to a network's success.

The benefits of Gadinis' shift away from generalized claims as to the wisdom and utility of networks also warrant attention. Like the tendency toward lumping, there is some logic to the normative orientation we have observed in the literature to date.

At the most obvious level, one might expect that any new phenomenon-networks included-would prompt a heavily normative discourse at the outset. The normative emphasis of the network literature might also be seen to align with some similar tendency in the international law literature generally. Against the backdrop of our emphasis on the nature of legal authority and democratic accountability in international institutions, it should perhaps be unsurprising that a new institutional alternative would trigger a strongly normative colloquy.

In moving us beyond lumping, Gadinis allows us to gain greater insight into the operation of networks. But he also enables us to evaluate their wisdom in the particular, rather than the abstract. Networks may thus be good at some things, but not others. Some may be good, and others bad, or good at some times, but not at others.

\section{The Challenges of Lumping, After Splitting}

In splitting the atom of transnational networks, however, Gadinis opens up a different challenge for their analysis. Once we have followed him down the path of splitting, we must face the question of whether any degree of lumping can be credibly accomplished - a question fairly asked even as to Gadinis' own (fairly general) clustering of networks into private, regulator, and ministry categories. Akin to the proverbial Humpty Dumpty, it may be hard to put together consistent and predictable categories of networks, once we have tasted the fruit of their significant differences.

This challenge of "re-lumping" (to coin a term) arises for several reasons, beginning with the subject-matter specificity of most networks. Networks — and especially Gadinis' private and regulator networks—are often designed to track the specialized expertise of their membership. And in an increasing complex world, such specialization tends to be particularly specialized.

This is apparent even in the case of Gadinis' own case studies. While the International Accounting Standards Board (IASB), IOSCO, and the Financial Action Task Force all are focused on financial regulation, the particularized expertise associated with reconciling financial statements has almost nothing to do with the curtailment of money laundering. Even the enforcement cooperation associated with IOSCO's MMOU, in fact, has little overlap with the accounting initiatives of the IASB.

The challenge of categorizing networks is further aggravated by the (related) fact of their idiosyncratic nature. Networks tend to emerge in response to particular needs and circumstances, and to have a fairly narrow focus. For that reason, in turn, their creation is often less formal — and legalistic - in nature, inviting further idiosyncrasy. As a result, strands of commonality may be more difficult to discern, and more subject to dispute.

The greatest obstacle to re-lumping networks, however, is the difficulty of identifying the appropriate characteristic(s) to serve as distinguishing criteria for categorizing them. Once again, this is apparent even in Gadinis' own analysis. 
In framing his argument, Gadinis speaks of the "lawmaking powers" of a given network as the key characteristic of interest. In his framework of "private, regulator, and ministry" networks, however, the critical feature would seem to be the identity of a network's members, rather than its lawmaking powers per se. The two are related, of course. But one might expect to find some significant variation in the formal—and especially the functional-lawmaking capacity of different regulators, executive branch officials, and private actors.

Even the identity of a network's members is not self-evidently the key characteristic for Gadinis, though. Membership is thus only one of the six facets of networks he identifies and evaluates as to each of his case studies: (1) Key motivation, (2) Strategy for drafting and adoption, (3) Membership, (4) Governance, (5) Implementation efforts, and (6) Sanctions. Some of the other five might be seen to follow from the identity of a network's members. On the other hand, a number of them-perhaps "strategy for drafting and adoption" most particularly — might arguably be more dispositive of a network's lawmaking powers than the identity of its members.

It should come as little surprise, then, that the lines Gadinis draws among his proposed categories of networks are subject to some reasonable challenge. While ministry networks may be particularly well-positioned to link multiple issue areas, regulator networks engage in a fair share of it as well-sometimes extending the reach of their members' domestic influence in the process. One might similarly wonder whether there is not some competitive dimension to the work of regulator networks, akin to what Gadinis sees within private networks. It is precisely in overlapping capital markets, thus, that securities regulators generally seek to extend their influence. While Gadinis is undoubtedly correct that power relations are likely to be particularly important in ministry networks, it is hard to imagine that the participants in private and regulator networks do not experience differential power and influence among their members as well.

In advancing the cause of splitting in the study of transnational networks, then, Gadinis' analysis forces us to face the potential difficulty of any lumping at all. If networks generally constitute too broad a category for analysis, "private, regulatory, and ministry networks" may not be much better.

\section{Gadinis' Lessons for the Study of Transnational Networks}

Nonetheless, Gadinis' analysis helps to reveal a number of important avenues for the future study of transnational networks. His case studies of particular networks, to begin, suggest the kind of "microanalysis of institutions" that will generate deeper insights into network structures in the years ahead. ${ }^{10}$ Such analysis should, in the first instance, be primarily oriented to teasing out the particular features and characteristics of particular networks. Only with such close analysis in hand should relevant hypotheses be brought to bear. At moments, thus, Gadinis' evaluation of his case studies has a certain feel of confirmation bias to it—a risk that future studies should carefully avoid.

Gadinis' passing suggestion of the lessons that the analysis of private, regulator, and ministry networks might learn from various fields of domestic legal study offers a similarly promising path for future analysis. The literatures of private lawmaking and self-regulatory organizations, of administrative law, and of executive power amidst crisis might be drawn upon yet more fully than in the past, to shed further light on transnational networks - and to enrich those domestic literatures in the meanwhile. ${ }^{11}$

10 See Edward L. Rubin, The New Legal Process, the Synthesis of Discourse, and the Microanalysis of Institutions, 109 HARV. L. REV. 1393 (1996). To be clear, some have already been engaging in just such close institutional analysis of individual networks. See, e.g., Janet Koven Levit, A Bottom-Up Approach to International Lawmaking: The Tale of Three Trade Finance Instruments, 30 YALE J. INT'L L. 125 (2005).

11 The Global Administrative Law literature, of course, has already yielded substantial fruit from its engagement of the domestic administrative law literature. See Benedict Kingsbury et al., The Emergence of Global Administrative Law, 68 LAW \& CONTEMP. PROBS. 15 (2005). 
Notwithstanding the limitations described above, Gadinis' typology of private, regulatory, and ministry networks points to a further important genre of future writing on transnational networks. Going forward, other scholars would do well to offer their own proposed "lumpings" of networks—-be they iterations of Gadinis' proposal, or entirely distinct possibilities.

With the accumulation of a collection of such alternatives, one might hope to see something of the spirit of the "legal families" discourse that shaped the comparative law literature for many years. ${ }^{12}$ In attempting to sort through the appropriate classification of national legal regimes into clusters of so-called families, our insight into the comparative features of those regimes was helpfully advanced. ${ }^{13}$ Similarly, a cacophony of potential classifications of transnational networks might help us to refine our understanding of the comparative characteristics of distinct networks.

Most broadly, Gadinis' effort to tease out the key characteristics of particular networks-and network types-suggests a final important path for the study of transnational networks. As described above, Gadinis variously engages lawmaking capacity, network membership, and subject-matter as important characteristics of individual networks. Likewise, their motives, procedures for drafting and adoption, governance structures, tools of implementation, and sanctions.

Yet other characteristics might also be identified, including size, degree of transparency, and institutional permanence. Future analysis might thus undertake to tease out the broadest universe of network characteristics and features to be considered-helping us to more fully understand both the ways in which networks are different and the same. This would allow students of transnational networks, in turn, to delineate the most important characteristics in shaping networks, in terms of both their impact and approach. Is size more likely to be central to the character and influence of a network, for example, or its ability to impose sanctions? In engaging the relative importance of different characteristics, our capacity to more fully understand transnational networks - and ultimately even to categorize them — can be expected to advance significantly.

As with the related articulation of a diversity of proposed lumpings of transnational networks, efforts to enumerate and prioritize network characteristics will necessarily generate some cacophony of possibilities and approaches. That is precisely what might be hoped for, though, in advancing the study of transnational networks after the split.

Much work remains to be done in the study of transnational networks. Stavros Gadinis has helped us to take a critical step, however, by opening up “the black box of network standard-setting." In doing the fox's work of splitting, he has moved us beyond the discourse that has characterized the network literature to date. And he has laid the groundwork for the critical work to come.

12 See Mariana Pargendler, The Rise and Decline of Legal Families, 60 Aм. J. ComP. L. 1043 (2012).

${ }^{13}$ As the legal families literature also makes clear, there can be diminishing returns to such efforts as well. At the current stage in our study of transnational networks, however, such a disclosure may be a source of meaningful insight. 